\title{
Efficacy and Safety of Switching from Low-Dose Statin to High-Intensity Statin for Primary Prevention in Type 2 Diabetes: A Randomized Controlled Trial
}

This article was published in the following Dove Press journal:

Diabetes, Metabolic Syndrome and Obesity: Targets and Therapy

\section{Nuntakorn Thongtang (D) \\ Jirasak Piyapromdee \\ Natthakan Tangkittikasem \\ Kittichai Samaithongcharoen \\ Nithiwat Srikanchanawat \\ Sutin Sriussadaporn \\ Division of Endocrinology and Metabolism, Department of Medicine, Faculty of Medicine Siriraj Hospital, Mahidol University, Bangkok, Thailand}

Correspondence: Nuntakorn Thongtang Division of Endocrinology and Metabolism, Department of Medicine, Faculty of Medicine Siriraj Hospital, Mahidol University, 2 Wanglang Road, Bangkoknoi, Bangkok 10700, Thailand

Tel +66 2-419-7799

Fax +66 2-419-7792

Email nuntakorn@hotmail.com
Introduction: Statin intensification is required in patients who have high-risk for cardiovascular events. However, it is unclear if this is needed in whom plasma LDL-C target was achieved with low-dose statin for primary prevention. We investigated the efficacy and safety of switching from low-dose statin to high-intensity statin among type 2 diabetes (T2D) who had achieved plasma LDL-C $<100 \mathrm{mg} / \mathrm{dl}$ with low-dose statin treatment.

Methods: T2D patients with no atherosclerotic cardiovascular disease who had plasma LDL-C level $<100 \mathrm{mg} / \mathrm{dl}$ while taking simvastatin $\leq 20 \mathrm{mg}$ /day were randomized to continue using the same dosage of simvastatin (low-dose statin group; LS) for 12 weeks, or to switch to atorvastatin $40 \mathrm{mg}$ / day for 6 weeks, and then, if tolerated, to atorvastatin $80 \mathrm{mg} /$ day for 6 weeks (high-intensity statin group; HS). Biochemical test and adverse events were evaluated at baseline, 6 weeks, and 12 weeks. Results: One hundred and fifty patients (76 LS, $74 \mathrm{HS}$, mean age $58.9 \pm 8.9$ years, $72 \%$ female) were included. The mean baseline plasma LDL-C level on statin was slightly higher in the HS group ( $71.9 \pm 13.6$ vs. $68.1 \pm 14.2 \mathrm{mg} / \mathrm{dl}, p=0.09$ ). The HS group had a significantly lower plasma LDL-C level at both 6 and 12 weeks (both $p<0.001$ ). Plasma LDL-C $<40 \mathrm{mg} / \mathrm{dl}$ was found more frequently in the HS group ( $23.0 \%$ vs. $3.9 \%, p<0.001)$. Discontinuation of statin due to adverse effects was more frequent in the HS group ( $5.4 \%$ vs. $1.3 \%$, p=0.38 for atorvastatin $40 \mathrm{mg} /$ day, $12.2 \%$ vs. $1.3 \%$, $p=0.03$ for atorvastatin $80 \mathrm{mg} /$ day). No serious adverse events were observed in either group.

Conclusion: Switching from low-dose statins to high-intensity statins resulted in a significant reduction in plasma LDL-C levels, and was fairly well tolerated during a 12 week study period.

Keywords: efficacy, safety, high-intensity statin, primary prevention, Thai patients, type 2 diabetes

\section{Introduction}

Type 2 diabetic patients (T2D) have an increased risk of atherosclerotic cardiovascular diseases (ASCVD), ${ }^{1}$ and statin therapy had been shown to reduce ASCVD events as compared with placebo in T2D. ${ }^{2,3}$ A meta-analysis of statin trials has shown that each 1.0 $\mathrm{mmol} / \mathrm{L}$ or $40 \mathrm{mg} / \mathrm{dL}$ reduction of plasma LDL-cholesterol (LDL-C) reducing the annual rate of the major vascular events by $21 \%{ }^{4}$ Moreover, intensive plasma LDL-C lowering has been shown to reduce cardiovascular events in high-risk patients. ${ }^{5-7}$ High-intensity statin treatment resulted in a significant greater reduction in the incidence of coronary death or myocardial infarction by $16 \%$ when compared to moderate-dose statins. ${ }^{8}$ There are currently two approaches to managing dyslipidemia. The first is based on the use of plasma LDL-C targets, and the second centers on statin intensity according to the ASCVD risks. 
The National Cholesterol Education program: Adult treatment panel (NCEP ATP III), ${ }^{9}$ the ESC/EAS Guidelines for the Management of Dyslipidaemias, ${ }^{10,11}$ and the 2017 American Association of Clinical Endocrinology (AACE) ${ }^{12}$ recommended using plasma LDL-C target. Plasma LDL-C target of less than $100 \mathrm{mg} / \mathrm{dl}$ is recommended in young T2D with no additional risk factors and/or no target organ damage. ${ }^{10,11}$ The guideline for Thai population (2016 Royal College of Physicians of Thailand Clinical Practice Guideline on Pharmacologic Therapy of Dyslipidemia) recommends plasma LDL-C target of $<100 \mathrm{mg} / \mathrm{dl}$ in all T2D patients for primary prevention. ${ }^{13}$ In contrast, the American College of cardiology/American Heart association (ACC/AHA) Guideline on the Treatment of Blood Cholesterol to Reduce Atherosclerotic Cardiovascular Risk in Adults ${ }^{14,15}$ and American Diabetes Association (ADA); Standard of Medical Care in Diabetes $2019^{11}$ recommended using moderateintensity statins (LDL-C reduction 30-50\%) or high-intensity statins (LDL-C reduction $>50 \%$ ) for primary prevention in T2D age 40-75 years old depending on their 10-year ASCVD risk. Low-intensity statins (LDL-C reduction $<30 \%$ ) were not recommended in diabetic patients. ${ }^{14,16}$

The efficacy of plasma LDL-C reduction has been shown to be greater in Asian population than in the Caucasians at similar statin dosages ${ }^{17,18}$ including our studies in Thai patients. ${ }^{19,20}$ We previously have shown that $38 \%$ of the patients using low- to moderate-intensity statins achieved LDL-C reduction of $>50 \%$ from baseline which is compatible with the LDL-C reduction efficacy of high-intensity statins. ${ }^{20}$ Thus, low- and moderate-intensity statins are commonly used in Thai T2D for primary prevention. It is still unclear if statin intensification is justified in type 2 diabetes who already achieved plasma LDL-C target with low-dose statin for primary prevention, although moderate- or high-intensity statin is recommended in the American guideline especially in diabetic patients with high cardiovascular risk.

Blood statin levels have shown to be higher in Asians than in the Caucasians after the administration of the same dose of statins. ${ }^{21}$ As a result; high-intensity statins are infrequently prescribed in Asian including Thailand ${ }^{22,23}$ especially for primary prevention in high-risk patients partly due to the fear of side effects. Although prior study has shown that high-intensity statins are safe in Asian, ${ }^{24,25}$ statin adverse reactions occur dose-dependently. ${ }^{26-28}$ In addition, the deleterious effect of very low plasma LDL-C level is still in doubt and some experts question whether it may result in an increased risk of intracerebral hemorrhage..$^{29,30}$ Therefore, the aim of this study was to investigate the efficacy and safety of switching from low-dose statin (LDL-C target-based regimen) to high-intensity statin (intensity-based regimen) among T2D patients who had already achieved plasma LDL-C targets $<100 \mathrm{mg} / \mathrm{dl}$ with lowdose statin treatment. Other pleiotropic effects (non-lipid effects) of statin therapy were also investigated.

\section{Materials and Methods Study Design and Study Population}

This randomized, open-label study was conducted at the Division of Endocrinology and Metabolism, Department of Medicine, Faculty of Medicine Siriraj Hospital, Mahidol University, Bangkok, Thailand during the April 2017 to January 2018 study period. The inclusion criteria were diagnosis of T2D, age 18-75 years, history of receiving a stable dose of simvastatin up to $20 \mathrm{mg}$ /day for at least 3 months prior to the start of the study, and plasma LDL-C level less than $100 \mathrm{mg} / \mathrm{dl}$ at the time of randomization. Patients having established ASCVD, decompensated liver cirrhosis or elevated plasma transaminase enzymes greater than 3 times the upper normal limit, chronic kidney disease stage 3-5, plasma creatine kinase (CPK) greater than 2 times the upper normal limit, and/ or concomitant use of ezetimibe were excluded. Stratified randomization by age and baseline glycated hemoglobin $\left(\mathrm{HbA}_{1 \mathrm{C}}\right)$ was performed. Patients were randomly assigned to continue using the same dosage of simvastatin (low-dose statin group; LS) for 12 weeks, or to switch to atorvastatin (Pfizer, Inc., New York, New York, USA) $40 \mathrm{mg} /$ day for 6 weeks, and then, if tolerated, to atorvastatin $80 \mathrm{mg} /$ day for 6 weeks (highintensity statin group; HS). Biochemical test results and statinrelated adverse events were evaluated at baseline, 6 weeks, and 12 weeks after randomization (Figure 1). Changes in muscle symptoms were recorded. Plasma lipids, aspartate transaminase (AST), alanine transaminase (ALT), creatine phosphokinase (CPK), and high-sensitivity C-reactive protein (hs-CRP) were measured every visit. Small dense LDL-C (sdLDL-C) and lipoprotein(a) were measured at baseline and at 12 weeks. Plasma total cholesterol and triglycerides (TG) were assayed enzymatically. High-density lipoprotein cholesterol (HDL-C) and direct LDL-C were measured using a homogenous enzymatic colorimetric assay (Roche Diagnostics, Basel, Switzerland). Calculated LDL-C was calculated using Friedewald formula. $\mathrm{HbA}_{1 \mathrm{C}}$ was measured using turbidimetric inhibition immunoassay (Roche Diagnostics). Lipoprotein(a) was measured using turbidimetric assay (Roche Diagnostics). Small density LDL-C was assessed using an LDL-EX SEIKEN Kit from Randox Laboratories Ltd. (Crumlin, United Kingdom). Study drug adherence was assessed by pill 


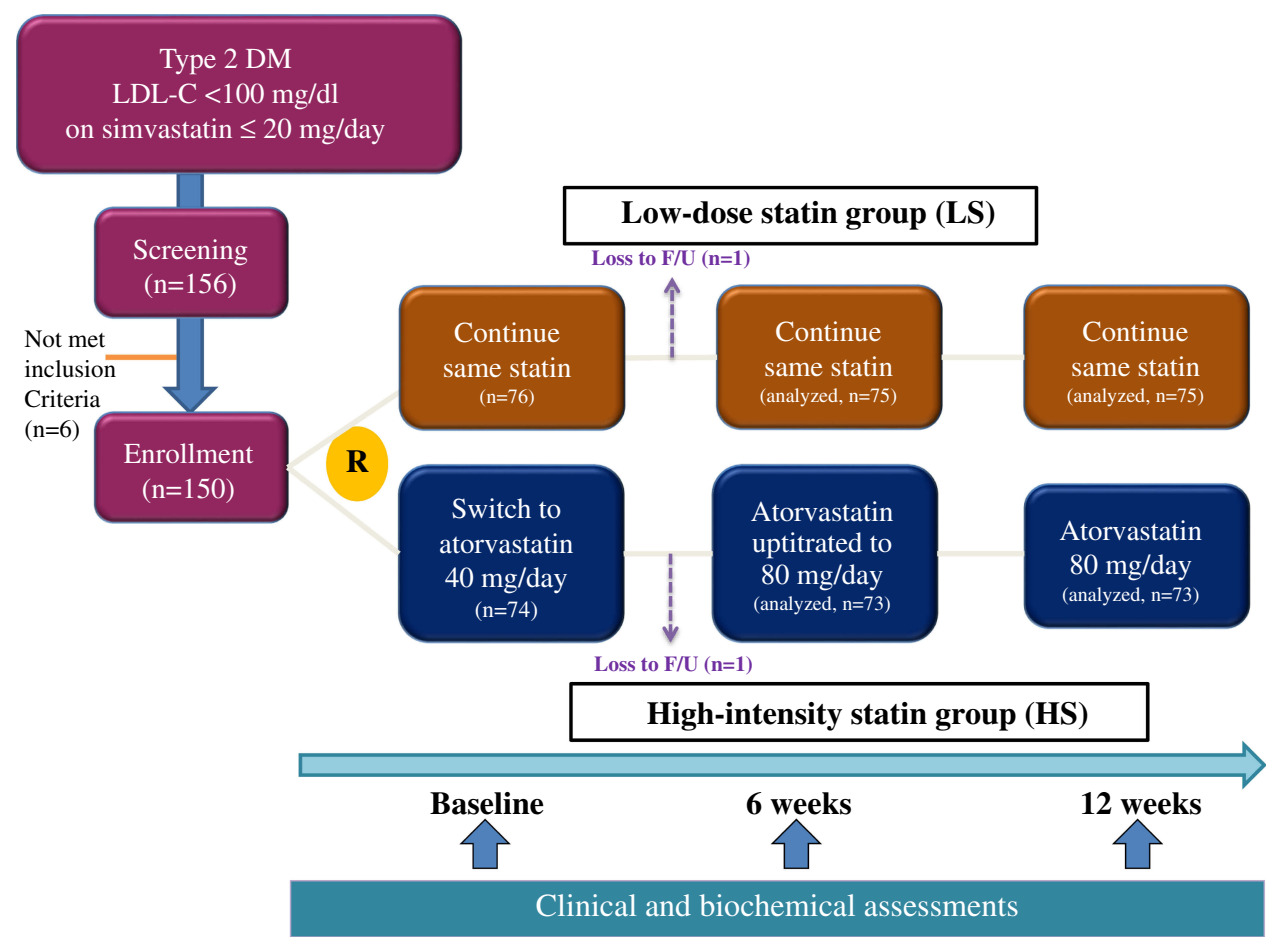

Figure I Flow diagram describing the study enrollment, randomization, treatment, and assessment process. Abbreviations: DM, diabetes mellitus; R, randomization; LDL-C, low-density lipoprotein cholesterol.

counting. The study protocol was reviewed and approved by the Siriraj Institutional Review Board (SIRB) (COA no. SI 680/2014). The trial was conducted in accordance with the Declaration of Helsinki. Written informed consent was obtained from all participants. The trial registration number is TCTR20180812001.

\section{Sample Size Calculation}

A previous study using atorvastatin $80 \mathrm{mg}$ /day had shown that the proportion of the patients who had plasma LDL-C level $<40 \mathrm{mg} / \mathrm{dl}$ was $11.7 \%$ when received atorvastatin treatment when mean plasma LDL-C at baseline was $104.51 \mathrm{mg} / \mathrm{dl}^{31}$ That same study found no incidence of plasma LDL-C $<40 \mathrm{mg} / \mathrm{dl}$ in patients receiving treatment with simvastatin. Using a significance level of 0.05 and a power of $80 \%$ to detect the difference in patients achieving plasma LDL-C $<40 \mathrm{mg} /$ $\mathrm{dL}$, a total of 142 patients were calculated. That sample size was increased by $5 \%$ to compensate for patient withdrawal for any reason, so 150 patients were recruited for this study.

\section{Statistical Analysis}

Descriptive statistics were used to summarize demographic and clinical data. Normally distributed continuous data were analyzed by $t$-test, and are presented as mean and standard deviation. Non-normally distributed data were evaluated by
Mann-Whitney $U$-test, and are shown as median and interquartile range. Categorical data were assessed using either Pearson's chi-square test or Fisher's exact test, and those results are given as number and percentage. A $p$-value $<0.05$ was considered statistically significant for all tests. All statistical analyses were performed using SPSS Statistics version 18.0 (SPSS, Inc., Chicago, IL, USA).

\section{Results}

Of the 156 patients that were screened for eligibility, 150 were enrolled in this study. Six subjects who had plasma LDL-C or other biochemical tests above the inclusion criteria were excluded. Seventy-six patients and 74 patients were randomized into the low-dose statin group (LS) and the high-intensity statin (HS) group, respectively. One patient in each study group was lost to follow-up. The patient in the HS group moved to another province, and the patient in the LS group decided not to return for the follow-up visits. The data were analyzed as a modified intention-to-treat analysis. Subjects who were randomized to the HS group but were unable to tolerate high-intensity statin were also included in the analysis. However, two patients who were lost to follow-up were not included (Figure 1). All patients who were unable to tolerate HS resumed treatment with simvastatin. 


\section{Baseline Characteristics of the Study Patients}

The mean age of patients was $58.9 \pm 8.9$ years, and $72 \%$ were female. The mean body mass index of subjects was 27.6 $\pm 4.5 \mathrm{~kg} / \mathrm{m}^{2}$. The study patients had a long duration of diabetes and had additional cardiovascular risk factor. The mean duration of diabetes at study enrollment was $10.6 \pm 7.3$ years, and hypertension was present in $75.3 \%$. Both groups had a similar prevalence of microvascular complications $(p>0.05)$. The overall prevalence of any stages of diabetic retinopathy was $20.0 \%$. The combined prevalence of micro- and macroalbuminuria was $22.7 \%$. Comorbidities, medications used, and cardiovascular risk factors were not statistically significantly different between groups.

Mean baseline plasma FBS and $\mathrm{HbA}_{1 \mathrm{c}}$ levels were 129.5 $\pm 37.3 \mathrm{mg} / \mathrm{dl}$ and $7.0 \pm 0.9 \%$, respectively. The mean baseline plasma calculated LDL-C level on simvastatin was 70.6 $\pm 14.6 \mathrm{mg} / \mathrm{dl}$. The HS group had a slightly higher mean baseline plasma LDL-C than the LS group $(71.9 \pm 13.6$ vs. $68.1 \pm 14.2 \mathrm{mg} /$ $\mathrm{dL}$, respectively; $p=0.09$ ). Myalgia was reported in $6.7 \%$ of patients at baseline; however, all patients had plasma creatine phosphokinase (CPK) levels within normal range. There were no significant differences in the mean plasma LDL-C, mean plasma $\mathrm{CPK}$, or plasma transaminase levels between groups at baseline. There was also no difference at baseline between groups relative to the proportion of patients with myalgia. Baseline characteristics and biochemical tests of all study patients, and compared between the LS and HS groups are shown in Table 1.

\section{Plasma Lipids During the Study}

The HS group had significantly $(p<0.001)$ lower plasma LDL$\mathrm{C}$ levels than the LS group at both 6 and 12 weeks (Figure 2). Mean plasma LDL-C levels in the LS group and HS group were $74.0 \pm 19.6 \mathrm{mg} / \mathrm{dl}$ and $54.9 \pm 25.1 \mathrm{mg} / \mathrm{dl}$, respectively, at 12 weeks. Atorvastatin $40 \mathrm{mg} /$ day significantly $(p<0.001)$ decreased plasma LDL-C by $20.3 \%$ from baseline, and atorvastatin $80 \mathrm{mg}$ /day decreased plasma LDL-C by $23.3 \%$ from baseline (Table 2). The mean difference in the percentage change in plasma LDL-C from baseline between groups was $22.7 \%$ at 6 weeks, and $33.9 \%$ at 12 weeks. Mean plasma total cholesterol (TC) and triglycerides (TG) at 12 weeks were also significantly lower in the HS group than in the LS group (TC: $125.4 \pm 30.0 \mathrm{mg} / \mathrm{dl}$ vs. $153.6 \pm 23.2 \mathrm{mg} / \mathrm{dl} ; p<0.001$, and TG: $97.2 \pm 41.2 \mathrm{mg} / \mathrm{dl}$ vs. $121.8 \pm 54.7 \mathrm{mg} / \mathrm{dl} ; p=0.002$ ). Plasma HDL-C levels were slightly higher in the LS group than in the HS group at 12 weeks $(55.1 \pm 13.4$ vs. $51.0 \pm 14.7 \mathrm{mg} / \mathrm{dl}$; $p=0.08)$. HS group patients had significantly greater reductions in sdLDL-C and hs-CRP levels from baseline with atorvastatin $80 \mathrm{mg} /$ day treatment. Percent changes in plasma lipids and hsCRP from baseline to 6 and 12 weeks are shown in Table 2 .

\section{Safety Data}

The incidence of adverse events leading to statin discontinuation was higher in the HS group than the LS group. The cumulative incidence did not reach statistical significant difference at visit 2 ( $5.4 \%$ vs. $1.3 \%, p=0.38)$; however, there was a statistically significant difference at visit $3(12.2 \%$ vs. $1.3 \%, p=0.03)$, as shown in Table 3A. One patient in the LS group had myositis from drug-drug interaction, and 4 patients in the HS group had various symptoms that led to statin discontinuation during visit 2 (i.e., 1 myalgia, 1 myositis, 1 urticaria, and 1 dizziness). In addition, 1 patient in the HS group had myositis, and 4 patients had rising of ALT $>2 x$ from baseline ALT levels at visit 3 . These four patients were asymptomatic, only plasma ALT elevations were found. The patient in the LS group took simvastatin together with clarithromycin that was prescribed from another hospital to treat pneumonia. Her plasma CPK level rose from $121 \mathrm{U} / \mathrm{L}$ to $4389 \mathrm{U} / \mathrm{L}$ without any muscle symptoms (normal range 0-190 U/L). After simvastatin withdrawal, her plasma CPK level decreased to within normal range $(71 \mathrm{U} / \mathrm{L})$.

Plasma calculated LDL-C $<40 \mathrm{mg} / \mathrm{dl}$ at any point during the 12-week study period was significantly more prevalent in the HS groups than in the LS group [17 events (23.0\%) vs. 3 events $(3.9 \%) ; p=0.001]$. All 3 patients in the LS group who had plasma LDL-C level $<40 \mathrm{mg} / \mathrm{dl}$ at 6 -weeks had a plasma LDL-C level $>40 \mathrm{mg} / \mathrm{dl}$ at the 12 -week follow-up. Among the low plasma LDL-C patients, 1 patient in the HS group had myalgia with a 2-fold elevation of plasma CPK (378 U/ L), and 2 patients had plasma AST and ALT $>2 x$ the upper normal limit at the 12-week follow-up. All 3 of those patients experienced improvement after atorvastatin discontinuation. No patients reported amnesia or memory impairment during the study period.

The incidence of reported muscle symptoms was greater in the HS group than in the LS group; however, the difference between groups was not statistically significant. Mean plasma CPK, AST, and ALT were also not significantly different between groups during the study period (Table 3B). There were no significant differences between groups relative to the prevalence of patients with elevated plasma CPK, AST, or ALT greater than 2 times the upper normal limit (Table 3C). In addition, there were no significant differences in changes in eGFR and urine microalbumin from baseline between groups. Median percent changes in urine microalbumin from baseline between the LS and HS group were $+14.63 \%$ ( -37.3 to 127.7 ) 
Table I Baseline Characteristics and Biochemical Tests of All Study Patients, and Compared Between the Low-Dose Statin and HighIntensity Statin Groups

\begin{tabular}{|c|c|c|c|c|}
\hline Parameters & All $(n=150)$ & Low-Dose Statin $(n=76)$ & High-Intensity Statin $(n=74)$ & $p$-value \\
\hline Age (years) & $58.8 \pm 8.9$ & $58.9 \pm 9.2$ & $58.8 \pm 8.6$ & 0.93 \\
\hline Female gender (n,\%) & $108,72.0 \%$ & $58,76.3 \%$ & $50,67.6 \%$ & 0.27 \\
\hline Hypertension (n,\%) & $113,75.3 \%$ & $57,75.0 \%$ & $56,75.7 \%$ & 0.92 \\
\hline Current smoker $(\mathrm{n}, \%)$ & $5,3.3 \%$ & $3,3.9 \%$ & $2,2.7 \%$ & 0.27 \\
\hline Alcohol use $(n, \%)$ & $19,12.7 \%$ & $10,13.2 \%$ & $9,12.2 \%$ & 0.85 \\
\hline Muscle symptoms (n,\%) & $10,6.7 \%$ & $6,7.9 \%$ & $4,5.4 \%$ & 0.75 \\
\hline \multicolumn{5}{|l|}{ Microvascular complications } \\
\hline -Proteinuria (n,\%) & $34,22.7 \%$ & $16,21.1 \%$ & $18,24.3 \%$ & 0.63 \\
\hline -Retinopathy (n,\%) & $30,20.0 \%$ & $14,18.4 \%$ & $16,21.6 \%$ & 0.11 \\
\hline -Abnormal monofilament test (n,\%) & $13,8.7 \%$ & $7,9.2 \%$ & $6,8.1 \%$ & 0.81 \\
\hline Body weight (kg) & $67.7 \pm 13.4$ & $68.4 \pm 12.4$ & $64.0 \pm 14.4$ & 0.52 \\
\hline Mean simvastatin dosages (mg/day) & $14.8 \pm 5.2$ & $|4.7 \pm 5|$. & $14.9 \pm 5.1$ & 0.82 \\
\hline Body-mass index $\left(\mathrm{kg} / \mathrm{m}^{2}\right)$ & $27.6 \pm 4.5$ & $27.9 \pm 4.4$ & $27.3 \pm 4.7$ & 0.40 \\
\hline Waist circumference $(\mathrm{cm})$ & $93.1 \pm 11.8$ & $93.5 \pm 12.2$ & $92.7 \pm 12.5$ & 0.70 \\
\hline $\mathrm{SBP}(\mathrm{mmHg})$ & $132.1 \pm 17.4$ & $132.9 \pm 16.9$ & $|3| .3 \pm 18.0$ & 0.59 \\
\hline $\mathrm{DBP}(\mathrm{mmHg})$ & $72.5 \pm 9.5$ & $72.2 \pm 10.0$ & $72.8 \pm 9.0$ & 0.67 \\
\hline FPG (mg/dl) & $129.5 \pm 37.3$ & $128.6 \pm 40.3$ & $130.4 \pm 34.1$ & 0.77 \\
\hline $\mathrm{HbA}_{\mathrm{IC}}(\%)$ & $7.0 \pm 0.9$ & $7.1 \pm 0.9$ & $7.0 \pm 0.9$ & 0.74 \\
\hline Total cholesterol (mg/dl) & $148.4 \pm \mid 9.1$ & $148.7 \pm 19.8$ & $148.0 \pm 18.5$ & 0.83 \\
\hline Triglycerides (mg/dl) & $106.0(76.0-157.0)$ & II 2.5 (82.0-I67.0) & $98.5(75.0-142.0)$ & 0.18 \\
\hline HDL-C (mg/dl) & $54.1 \pm 13.6$ & $55.0 \pm \mid 3.7$ & $53.1 \pm 13.6$ & 0.39 \\
\hline Calculated LDL-C (mg/dl) & $70.0 \pm 14.0$ & $68.1 \pm 14.2$ & $71.9 \pm 13.6$ & 0.09 \\
\hline Direct LDL-C (mg/dl) & $85.5 \pm 16.0$ & $84.1 \pm 14.0$ & $86.9 \pm 14.8$ & 0.27 \\
\hline Lipoprotein(a) (mg/dl) & $19.5(7.4-60.7)$ & $17.6(8.0-53.8)$ & $21.2(7.4-66.6)$ & 0.50 \\
\hline sdLDL-C (mg/dl)** & $31.6 \pm 13.6$ & $32.4 \pm \mid 4.3$ & $31.1 \pm 13.2$ & 0.64 \\
\hline eGFR (mL/min/l.73m2) & $84.8 \pm 18.3$ & $84.2 \pm 19.5$ & $85.4 \pm 17.1$ & 0.70 \\
\hline Urine microalbumin (mg/g.Cr) & $7.3(3.9-19.6)$ & $7.3(3.5-18.3)$ & $7.4(42-22.2)$ & 0.38 \\
\hline CPK (U/L) (normal range 0-190) & $123.9 \pm 57.3$ & $116.7 \pm 54.7$ & $|3| .3 \pm 59.3$ & 0.12 \\
\hline AST (U/L) (normal range $0-40$ ) & $23.5 \pm 11.3$ & $22.3 \pm 9.6$ & $24.8 \pm 12.8$ & 0.18 \\
\hline ALT (U/L) (normal range 0-4I) & $23.5 \pm 14.4$ & $22.3 \pm 12.8$ & $24.7 \pm 16.1$ & 0.32 \\
\hline hs-CRP (mg/L) & $1.2(0.6-2.9)$ & I.I (0.57-2.9) & $1.2(0.7-2.9)$ & 0.71 \\
\hline
\end{tabular}

Notes: A p-value $<0.05$ indicates statistical significance. Data presented at mean (standard deviation), number and percentage, or median and interquartile range. $* *$ sdLDL-C was measured in 39 patients in the LS group, and in 63 patients in the HS group.

Abbreviations: SBP, systolic blood pressure; DBP, diastolic blood pressure; FPG, fasting plasma glucose; HbA $\mathrm{Ic}_{\mathrm{c}}$, glycated hemoglobin; HDL-C, high-density lipoprotein cholesterol; LDL-C, low-density lipoprotein cholesterol; sdLDL-C, small dense LDL cholesterol; eGFR, estimated glomerular filtration rate; CPK, creatine phosphokinase; AST, aspartate aminotransferase; ALT, alanine aminotransferase; hs-CRP, high-sensitivity C-reactive protein.

vs. $-6.40 \%$ ( -33.4 to 70.9$) ; p=0.12$. None of the study patients had cardiovascular events during the study period.

\section{Discussion}

We have found that switching to high-intensity statin treatment resulted in a significantly greater reduction in plasma LDL-C levels than continuing the use of low-dose statin in T2D patients who had already achieved a low plasma LDL-C level from lowdose statin treatment (mean baseline plasma LDL-C 70.6 $\pm 14.6 \mathrm{mg} / \mathrm{dl}$ ). Plasma total cholesterol and small dense LDL$\mathrm{C}$ were also significantly reduced; however, plasma HDL-C was also slightly decreased by $4.3 \%$ with HS treatment.
Most adults with T2D have an indication for statin treatment. In Thailand, low-dose statin use is common in routine clinical practice; however, high-intensity statins are rarely prescribed for primary prevention. This trend is due to both the enhanced response of Asians to lowdose statin therapy for LDL-C reduction ${ }^{17,19,20}$ and the fear of the side effects associated with high-intensity statins. Lipid-lowering treatment should be adjusted to higher intensity statin or to the use of combination therapy if plasma LDL-C level is still above the target $(>100 \mathrm{mg} / \mathrm{dl})$. However, should treatment be intensified in Asian patients who have already achieved the plasma 
Plasma LDL-C level (mg/dl)

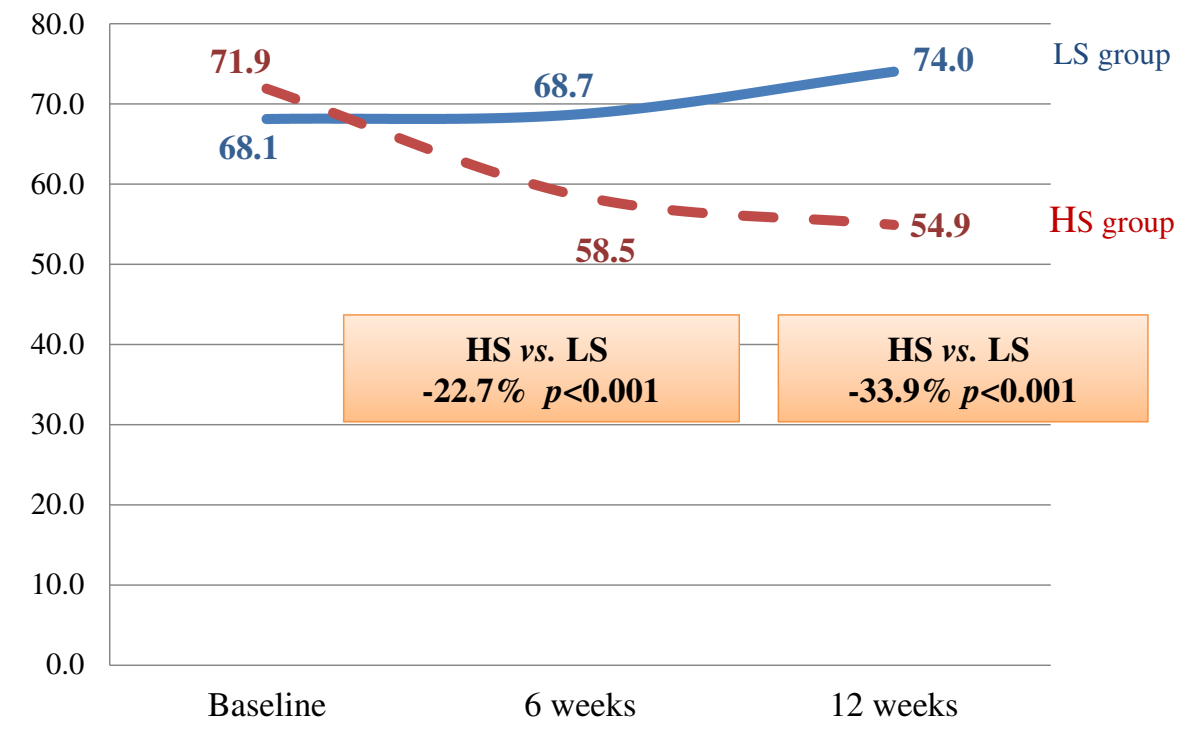

Figure 2 Plasma LDL-C levels in the two treatment groups during the study period. Abbreviations: HS, high-intensity statin group; LS, low-dose statin group.

LDL-C target with low-dose statin for primary prevention? A previous study in the Japanese population reported that an $18 \%$ reduction in plasma LDL-C levels with low-dose statins yielded a reduction in cardiovascular risk similar to the reduction observed in Western trials that included patients on higher statin doses. ${ }^{32}$ According to the local guideline using plasma LDL-C targets, there is no need to adjust the treatment regimen. However, the recent ESC guideline recommends plasma LDL-C target $<70 \mathrm{mg} / \mathrm{dl}$ in T2D with long duration of diabetes or having additional risk factor as our study patients. ${ }^{33}$ Moreover, high-intensity statins are recommended for primary prevention in T2D with diabetes duration greater than 10 years according to the ADA
$2019^{11}$ and the ACC/AHA $2018^{15}$ guidelines, thus making statin intensification justified for our study patients according to the American and the European guidelines.

Recent clinical trials in very-high-risk population revealed a further reduction in cardiovascular events with intensive lowering of plasma LDL-C levels to $<70 \mathrm{mg} / \mathrm{dl}$ for secondary prevention. ${ }^{5-7}$ However, most of these clinical studies using high-intensity statins were conducted in Caucasians with very few Asians included. Moreover, randomized controlled trials studying high-intensity statins in the Asian population for primary prevention in T2D are limited. Our study showed that switching from low-dose statin (simvastatin at an average dose of $15 \mathrm{mg} /$ day) to high-intensity statins resulted in $20.0-23.0 \%$ reduction in plasma LDL-C from baseline. A previous study in

Table 2 Changes in Biochemical Parameters from Baseline to 6 and 12 Weeks

\begin{tabular}{|c|c|c|c|c|c|c|}
\hline \multirow[t]{2}{*}{ Parameters } & \multicolumn{2}{|c|}{ \% Change from Baseline to 6 Weeks } & \multirow[t]{2}{*}{ p-value* } & \multicolumn{2}{|c|}{$\%$ Change from Baseline to 12 Weeks } & \multirow[t]{2}{*}{$p$-value* } \\
\hline & $\begin{array}{l}\text { Low-Dose Statin } \\
(\mathbf{N}=75)\end{array}$ & $\begin{array}{l}\text { Atorvastatin } 40 \mathrm{mg} / \mathrm{d} \\
(\mathrm{N}=73)\end{array}$ & & $\begin{array}{l}\text { Low-Dose Statin } \\
(\mathbf{N}=75)\end{array}$ & $\begin{array}{l}\text { Atorvastatin } 80 \mathrm{mg} / \mathrm{d} \\
(\mathrm{N}=73)\end{array}$ & \\
\hline Cholesterol & $+0.7 \pm 13.5$ & $-12.5 \pm 13.8$ & $<0.001$ & $+3.9 \pm 14.1$ & $-15.3 \pm 16.4$ & $<0.001$ \\
\hline Triglycerides & $-4.7(-19.1$ to 19.7$)$ & $-13.6(-29.7$ to 10.6$)$ & 0.069 & $-3.7(-21.5$ to 16.8$)$ & $-13.4(-28.6$ to 4.0$)$ & 0.045 \\
\hline HDL-C & $+2.6 \pm 14.8$ & $-3.2 \pm 11.5$ & 0.009 & $+2.0 \pm 14.0$ & $-4.3 \pm 13.7$ & 0.007 \\
\hline Calculated LDL-C & $+2.4 \pm 24.9$ & $-20.3 \pm 19.0$ & $<0.001$ & $+10.6 \pm 27.9$ & $-23.3 \pm 30.1$ & $<0.001$ \\
\hline Direct LDL-C & $+1.8 \pm 22.0$ & $-17.6 \pm 18.2$ & $<0.001$ & $+9.6 \pm 25.7$ & $-19.8 \pm 25.8$ & $<0.001$ \\
\hline sdLDL-C & N/A & $N / A$ & & $+20.4 \pm 41.4$ & $-10.8 \pm 38.9$ & 0.001 \\
\hline hs-CRP & $3.3(-18.8$ to 49.6$)$ & $-23.9(-52.0$ to 7.3$)$ & $<0.001$ & 5.1 ( -25.0 to 27.9$)$ & $-21.2(-54.1$ to 6.8$)$ & 0.006 \\
\hline
\end{tabular}

Notes: Data reported as mean \pm standard deviation or median (interquartile range). A $p$-value $<0.05$ indicates statistical significance. ${ }^{*} p$-value of the differences between groups. Abbreviations: HDL-C, high-density lipoprotein cholesterol; LDL-C, low-density lipoprotein cholesterol; sdLDL-C, small dense LDL cholesterol; hs-CRP, high-sensitivity C-reactive protein; N/A, not available. 
Table 3 Any Adverse Events Related to Statin Used

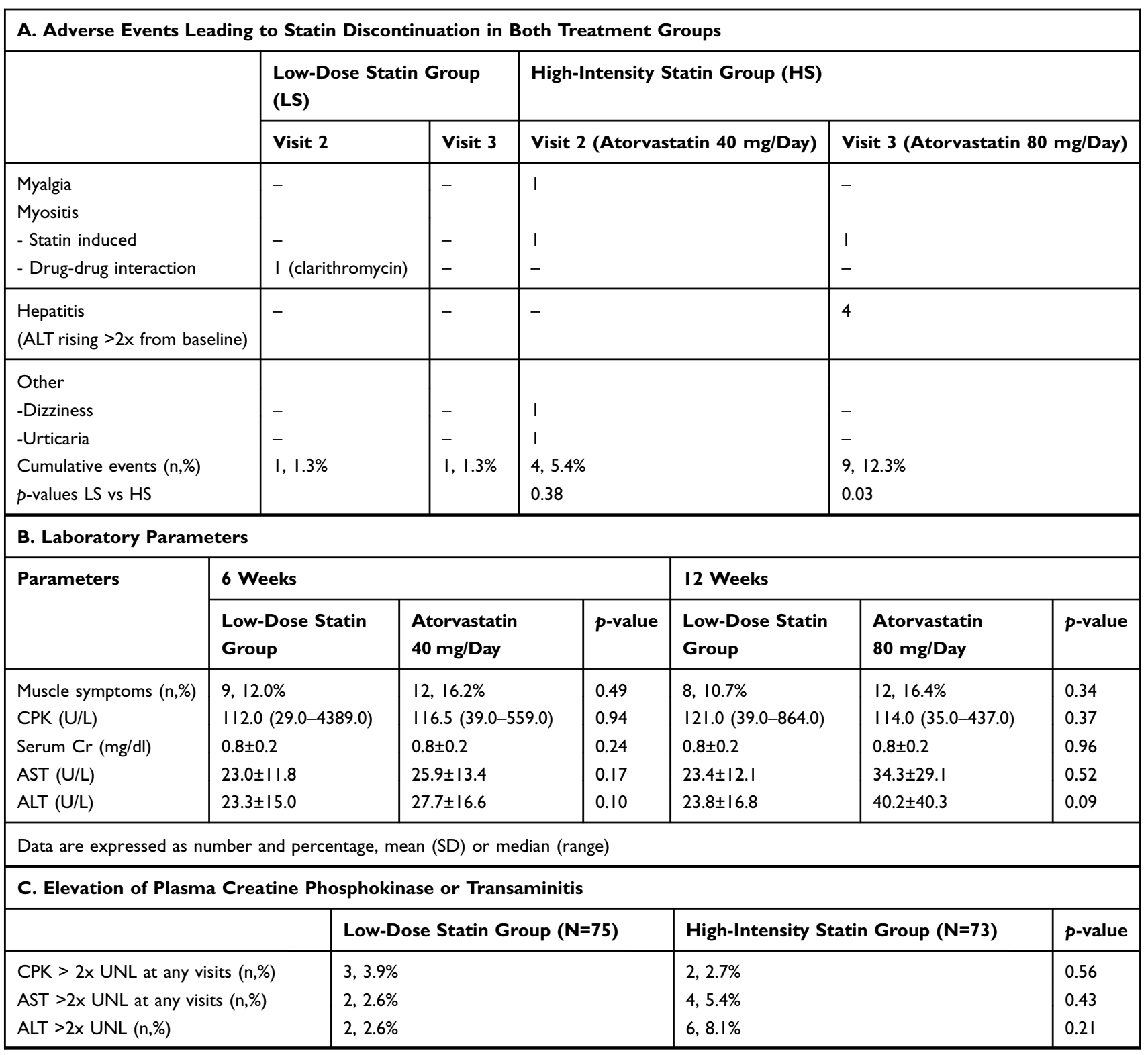

Caucasians has found that the efficacy in plasma LDL-C reduction of simvastatin $20 \mathrm{mg} /$ day is equivalent to atorvastatin $10 \mathrm{mg} / \mathrm{day}^{34}$ thus increasing the dose from atorvastatin $10 \mathrm{mg} /$ day to 40 and $80 \mathrm{mg} /$ day should result in addition plasma LDL-C lowering of approximately $12 \%$ and $18 \%$, respectively, according to the rule of six. ${ }^{35}$ Therefore, switching statins in our study population resulted in a greater reduction in plasma LDL$\mathrm{C}$ than expected in the Caucasians ( $12 \%$ vs $20 \%$ for atorvastatin $40 \mathrm{mg} /$ day, and $18 \%$ vs $23 \%$ for atorvastatin $80 \mathrm{mg} /$ day). These data support the previous finding of heightened response of plasma LDL-C lowering by statin in Asians.

We also found that there was a $10.8 \%$ reduction in small dense LDL-C with high-intensity statin treatment.
Small dense LDL is considered more atherogenic than large buoyant LDL; thus, a lowering of sdLDL-C levels should provide additional cardiovascular protection benefit in this patient population.

In addition, statins have a complex array of pleiotropic effects, including amelioration of endothelial dysfunction, increased nitric oxide bioavailability, antioxidant properties, and inhibition of inflammation, which are unrelated to their lipid-lowering effect. It is still unclear whether these pleiotropic effects increased with higher statin dose. We found that the HS group had a greater reduction in hs-CRP than the LS group, which supports the anti-inflammatory effect of high-intensity statins. 
The risk of having side effects, including muscle and liver injury, from statin increased dose-dependently. These explain the higher prevalence of adverse events leading to statin discontinuation in the HS group than the LS group. Atorvastatin at a dose of $40 \mathrm{mg} /$ day is more tolerable than at a dose of $80 \mathrm{mg} /$ day.

The prevalence of having very low plasma LDL-C levels was significantly higher in the HS group than the LS group in our study. Cholesterol is an essential nutrient to human body. Therefore, there are concerns for the safety of having very low plasma LDL-C levels. Previous study reported an increased risk of hemorrhagic stroke with intensive statin treatment. ${ }^{18}$ Some studies reported that adverse events were associated with statin dosage and that low plasma LDL-C level $<40 \mathrm{mg} / \mathrm{dl}$ may increase the risk of cerebrovascular accident. ${ }^{11,12}$ However, the results of a subsequent study did not support those previous findings. ${ }^{19}$ In addition, a 2006 retrospective analysis of over 14,000 patients found no difference in the incidence of myalgia between patients taking atorvastatin $80 \mathrm{mg}$ daily (intensive dose) and those taking atorvastatin $10 \mathrm{mg}$ (low dose), and no cases of rhabdomyolysis were reported. ${ }^{13} \mathrm{We}$ did not observe any serious adverse events (i.e., rhabdomyolysis, acute hepatitis, amnesia) among patients who had achieved plasma LDL-C $<40 \mathrm{mg} / \mathrm{dl}$ during the study period, which supports the safety of highintensity statin in Thai T2D for at least 12 weeks. However, longterm safety data of having very low plasma LDL-C level are still required. Our study was aimed to investigate the tolerability of statin intensification. All study subjects recruited were able to tolerate low-dose statin, while those who were unable to tolerate low-dose statin were excluded; therefore,; the overall tolerability to high-intensity statin might be higher than usual.

The objective of this randomized controlled trial was to investigate the benefit of high-intensity statin use for primary prevention in T2D patients, which is considered a high-risk population for cardiovascular events. Our study has some limitations; longer follow-up studies are required to ensure the safety of high-intensity statin therapy in the long term. In addition, future study addressing cardiovascular outcome reduction with intensive plasma LDL-C lowering for primary prevention in $\mathrm{T} 2 \mathrm{D}$ is still required.

\section{Conclusion}

Switching from low-dose statins to high-intensity statins resulted in a significant reduction in plasma LDL-C levels in T2D who already had low plasma LDL-C level on lowdose statin. The high-intensity statins were fairly well tolerated during the 12-week study period.

\section{Data Sharing Statement}

The dataset used and/or analyzed during the current study are available from the corresponding author on reasonable request. The data in the electronic file will be available for 5 years.

\section{Acknowledgments}

The authors gratefully acknowledge the patients who generously agreed to participate in this study, and Ms. Khemajira Karaketklang, Research Department, Faculty of Medicine Siriraj Hospital, Mahidol University for assistance with statistical analysis. The manuscript was proofread by a native English speaker, Mr. Kevin Jones, International College, Khon Kaen University.

\section{Funding}

This study was partially funded by a Siriraj Research Grant from the Faculty of Medicine Siriraj Hospital, Mahidol University, Bangkok, Thailand (grant no. R015936001), and partially funded by an investigatorinitiated grant from Pfizer, Inc. The funders have no role in the study conduct, data interpretation, and manuscript writing.

\section{Disclosure}

The authors report no conflicts of interest in this work.

\section{References}

1. Haffner SM, Lehto S, Ronnemaa T, Pyorala K, Laakso M. Mortality from coronary heart disease in subjects with type 2 diabetes and in nondiabetic subjects with and without prior myocardial infarction. $N$ Engl J Med. 1998;339(4):229-234. doi:10.1056/NEJM199807233390404

2. Colhoun HM, Betteridge DJ, Durrington PN, et al. Primary prevention of cardiovascular disease with atorvastatin in type 2 diabetes in the Collaborative Atorvastatin Diabetes Study (CARDS): multicentre randomised placebo-controlled trial. Lancet. 2004;364(9435):685-696. doi:10.1016/S0140-6736(04)16895-5

3. Cholesterol Treatment Trialists C, Kearney PM, Blackwell L, et al. Efficacy of cholesterol-lowering therapy in 18,686 people with diabetes in 14 randomised trials of statins: a meta-analysis. Lancet. 2008;371(9607):117-125.

4. Cholesterol Treatment Trialists C, Baigent C, Blackwell L, et al. Efficacy and safety of more intensive lowering of LDL cholesterol: a meta-analysis of data from 170,000 participants in 26 randomised trials. Lancet. 2010;376(9753):1670-1681.

5. Cannon CP, Blazing MA, Giugliano RP, et al. Ezetimibe added to statin therapy after acute coronary syndromes. $N$ Engl J Med. 2015;372(25):2387-2397. doi:10.1056/NEJMoa1410489

6. Sabatine MS, Giugliano RP, Keech AC, et al. Evolocumab and clinical outcomes in patients with cardiovascular disease. $N$ Engl J Med. 2017;376(18):1713-1722. doi:10.1056/NEJMoa1615664

7. Schwartz GG, Steg PG, Szarek M, et al. Alirocumab and cardiovascular outcomes after acute coronary syndrome. $N$ Engl $\mathrm{J} \mathrm{Med.}$ 2018;379(22):2097-2107. doi:10.1056/NEJMoa1801174 
8. Cannon CP, Steinberg BA, Murphy SA, Mega JL, Braunwald E. Meta-analysis of cardiovascular outcomes trials comparing intensive versus moderate statin therapy. $J$ Am Coll Cardiol. 2006;48 (3):438-445. doi:10.1016/j.jacc.2006.04.070

9. National Cholesterol Education Program Expert Panel on Detection E, Treatment of High Blood Cholesterol in A. Third report of the National Cholesterol Education Program (NCEP) expert panel on detection, evaluation, and treatment of high blood cholesterol in adults (adult treatment panel III) final report. Circulation. 2002;106 (25):3143-3421. doi:10.1161/circ.106.25.3143

10. Catapano AL, Graham I, De Backer G, et al. 2016 ESC/EAS guidelines for the management of dyslipidaemias. Eur Heart J. 2016;37 (39):2999-3058. doi:10.1093/eurheartj/ehw272

11. American Diabetes Association. 10. Cardiovascular disease and risk management: standards of medical care in diabetes-2019. Diabetes Care. 2019;42(Supplement1):S103-S123.

12. Jellinger PS, Handelsman Y, Rosenblit PD, et al. American Association of Clinical Endocrinologists and American College of Endocrinology guidelines for management of dyslipidemia and prevention of cardiovascular disease. Endocr Pract. 2017;23(Suppl 2):1-87. doi:10.4158/EP171764.APPGL

13. 2016 RCPT dyslipidemia clinical practice guideline on pharmacological therapy of dyslipidemia for atherosclerosis cardiovascular disease prevention. Available from: http://www.thaiheart.org/Download/2016RCPT-Dyslipidemia-Guideline.html. Accessed January 18, 2020.

14. Stone NJ, Robinson JG, Lichtenstein AH, et al. 2013 ACC/AHA guideline on the treatment of blood cholesterol to reduce atherosclerotic cardiovascular risk in adults: a report of the American College of Cardiology/ American Heart Association task force on practice guidelines. J Am Coll Cardiol. 2014;63(25Pt B):2889-2934. doi:10.1016/j.jacc.2013.11.002

15. Grundy SM, Stone NJ, Bailey AL, et al. 2018 AHA/ACC/AACVPR/ AAPA/ABC/ACPM/ADA/AGS/APhA/ASPC/NLA/PCNA guideline on the management of blood cholesterol: a report of the American College of Cardiology/American Heart Association task force on clinical practice guidelines. Circulation. 2019;139(25):e1082-e1143.

16. American Diabetes A. 9. Cardiovascular disease and risk management: standards of medical care in diabetes-2018. Diabetes Care. 2018;41(Suppl 1):S86-S104. doi:10.2337/dc18-S009

17. Liao JK. Safety and efficacy of statins in Asians. Am J Cardiol. 2007;99(3):410-414. doi:10.1016/j.amjcard.2006.08.051

18. Wang P. Statin dose in Asians: is pharmacogenetics relevant? Pharmacogenomics. 2011;12(11):1605-1615. doi:10.2217/pgs.11.98

19. Lee B, Dumrongkitchaiporn K, Sriussadaporn S. Thongtang N statin intensity regimens in Thai type 2 diabetic patients who achieved LDL-C targets. J Med Assoc Thai. 2017;100(5):603-611.

20. Thongtang N, Sitthananun C, Sriussadaporn S, Nitiyanant W. Efficacy of low- and moderate-intensity statins for achieving low- density lipoprotein cholesterol targets in Thai type 2 diabetic patients. $J$ Diabetes Metab Disord. 2017;16:6. doi:10.1186/s40200-017-0290-x

21. Lee E, Ryan S, Birmingham B, et al. Rosuvastatin pharmacokinetics and pharmacogenetics in white and Asian subjects residing in the same environment. Clin Pharmacol Ther. 2005;78(4):330-341. doi:10.1016/j.clpt.2005.06.013
22. Poh KK, Ambegaonkar B, Baxter CA, et al. Low-density lipoprotein cholesterol target attainment in patients with stable or acute coronary heart disease in the Asia-Pacific region: results from the Dyslipidemia International Study II. Eur J Prev Cardiol. 2018;25 (18):1950-1963. doi:10.1177/2047487318798927

23. Ye P. The Chinese dose of statin. Cardiol Plus 2016;1(4):1-5.

24. Chan JC, Kong AP, Bao W, Fayyad R, Laskey R. Safety of atorvastatin in Asian patients within clinical trials. Cardiovasc Ther. 2016;34 (6):431-440. doi:10.1111/1755-5922.12214

25. Li DQ, Kim RB, McArthur E, et al. Statin safety in Chinese: a population-based study of older adults. PLoS One. 2016;11(3): e0150990. doi:10.1371/journal.pone.0150990

26. Preiss D, Seshasai SR, Welsh P, et al. Risk of incident diabetes with intensive-dose compared with moderate-dose statin therapy: a meta-analysis. JAMA. 2011;305(24):2556-2564. doi:10.1001/jama.201 1.860

27. Maki KC, Ridker PM, Brown WV, Grundy SM, Sattar N, The Diabetes Subpanel of the National Lipid Association Expert P. An assessment by the statin diabetes safety task force: 2014 update. J Clin Lipidol. 2014;8(3 Supp1):S17-S29. doi:10.1016/j. jacl.2014.02.012

28. Mach F, Ray KK, Wiklund O, et al. Adverse effects of statin therapy: perception vs. the evidence - focus on glucose homeostasis, cognitive, renal and hepatic function, haemorrhagic stroke and cataract. Eur Heart J. 2018;39(27):2526-2539. doi:10.1093/eurheartj/ehy182

29. Amarenco P, Bogousslavsky J, Callahan A 3rd, et al. High-dose atorvastatin after stroke or transient ischemic attack. $N$ Engl J Med. 2006;355(6):549-559.

30. Noda $\mathrm{H}$, Iso $\mathrm{H}$, Irie $\mathrm{F}$, et al. Low-density lipoprotein cholesterol concentrations and death due to intraparenchymal hemorrhage: the Ibaraki Prefectural Health Study. Circulation. 2009;119 (16):2136-2145. doi:10.1161/CIRCULATIONAHA.108.795666

31. Newman C, Tsai J, Szarek M, Luo D, Gibson E. Comparative safety of atorvastatin $80 \mathrm{mg}$ versus $10 \mathrm{mg}$ derived from analysis of 49 completed trials in 14,236 patients. Am J Cardiol. 2006;97 (1):61-67. doi:10.1016/j.amjcard.2005.07.108

32. Nakamura H, Arakawa K, Itakura H, et al. Primary prevention of cardiovascular disease with pravastatin in Japan (MEGA study): a prospective randomised controlled trial. Lancet. 2006;368 (9542):1155-1163. doi:10.1016/S0140-6736(06)69472-5

33. Mach F, Baigent C, Catapano AL, et al. 2019 ESC/EAS Guidelines for the management of dyslipidaemias: lipid modification to reduce cardiovascular risk. Eur Heart J. 2019;41(1):111-188.

34. Jones P, Davidson M, Stein E, et al. Comparison of the efficacy and safety of rosuvastatin versus atorvastatin, simvastatin, and pravastatin across doses (STELLAR* trial). Am J Cardiol. 2003;92(2):152-160. doi:10.1016/S0002-9149(03)00530-7

35. Adams S, Tsang M, Wright J. Lipid-lowering efficacy of atorvastatin. Cochrane Database Syst Rev. 2015;(3):CD008226. doi:10.1002/ 14651858.CD008226.pub3

\section{Publish your work in this journal}

Diabetes, Metabolic Syndrome and Obesity: Targets and Therapy is an international, peer-reviewed open-access journal committed to the rapid publication of the latest laboratory and clinical findings in the fields of diabetes, metabolic syndrome and obesity research. Original research, review, case reports, hypothesis formation, expert opinion and commentaries are all considered for publication. The manuscript management system is completely online and includes a very quick and fair peer-review system, which is all easy to use. Visit http://www.dovepress.com/testimonials.php to read real quotes from published authors. 